\title{
Evaluation of Measurement Accuracy of Underground Thermometers Using Steel-Pipe Piles
}

\author{
Masahito Oguma, Ayako Funabiki and Mitsuru Endo \\ Department of Mechanical Engineering, College of Engineering, Nihon University, Koriyama 963-8642, Japan
}

Received: April 07, 2016 / Accepted: May 13, 2016 / Published: July 31, 2016.

\begin{abstract}
For ground source heat utilization systems, pile heat exchangers are sometimes used. In order for these systems to achieve high performance, control of the system dynamics is important, and the underground temperature must be known. Typically, underground temperature is measured using a thermometer in a borehole. However, in the case of pile heat exchangers, a different method is required, making the system expensive to set up. To overcome this problem, the installation of underground thermometers in the heat exchanger piles themselves is proposed in the present study. The proposed thermometer system consists of thermocouples packed in grout such as silica sand within the piles. However, there is a possibility of measurement errors due to vertical thermal conduction in the steel pipes, and it is important to estimate the measurement accuracy before the development of this system. In the present study, the measurement accuracy is estimated using numerical simulations and then confirmed experimentally. The underground temperature profiles inside and outside the pile are compared. The results indicate that the proposed system offers sufficient accuracy for application to pile heat exchangers.
\end{abstract}

Key words: Heat conduction, underground thermometer, pile heat exchanger.

\section{Introduction}

Air conditioning using geothermal heat is attractive from a thermal engineering perspective $[1,2]$. However, system installation costs are extremely high, which is a barrier to their popularization. One of the main costs is for the installation of the subterranean heat exchanger [3].

In Japan, many urban areas are situated on alluvial or coastal plains, such as the Kanto Plain, and are constructed on soft ground. In the light of the great east Japan earthquake disaster, attention has focused on housing that is more resilient to disasters, and foundation piles [4] such as embedded piles by rotation have sometimes been selected as foundation reinforcement.

Accordingly, the use of such foundation piles as subterranean heat exchangers to reduce system costs

Correspondingauthor: Masahito Oguma, professor, research fields: heat transfer, thermal engineering, and renewable energy. has been proposed $[5,6]$.

Since this method of shallow geothermal heat usage is based on residential foundation piles, the configuration of the subterranean heat exchanger itself depends on the layout of the house, making it impossible to freely specify. Accordingly, there are cases whereby the heat exchange well interval is around $2 \mathrm{~m}$, which is shorter than the conventionally recommended interval of $4 \mathrm{~m}$ [7]. In this situation, the effect of thermal interference due to collection/ radiation of heat among subterranean heat exchangers, which conventional designs attempt to avoid, is non-negligible. Furthermore, with respect to shallow geothermal heat usage, although a natural heat supply is expected from below the subterranean heat exchangers and from the ground surface [8], the soil heat capacity is not large because of the shallow point of application, and sudden drops in the thermal performance of the system are expected due to factors such as excessive soil cooling, depending on the use of heating and cooling within a residence. 
Performance is known to drop during long periods of geothermal heat collection. Suspending heat collection for a certain period of time when the soil temperature drops has been investigated as a measure for restoring operability. This allows heat to flow from soil in the outer circumference of the subterranean heat exchanger into the soil in its immediate vicinity, thereby restoring the temperature. This has been found to be effective in increasing heat collection performance.

Accordingly, to continuously utilize shallow geothermal heat by means of a foundation pile or other vertical subterranean heat exchanger, it is important to manage the subterranean temperature, which in turn necessitates monitoring it.

Soil temperature is often measured using an underground thermometer consisting of a temperature sensor placed on the surface of a small-diameter borehole [6]. Although the cost of producing the borehole is low because of its small diameter, several temperature sensors must be inserted into it, and workability deteriorates as a result. If the borehole is made larger, although workability improves, the production cost increases. A method exists whereby brine is circulated through a subterranean heat exchanger when there is no heat collection load, and the equilibrium temperature is measured [7], but this requires temporarily suspending air-conditioning for a certain period until the temperature reaches equilibrium, making it an impractical selection. Furthermore, in the case of using geothermal heat and steel-pipe piles, a rotating intrusion method is used. A different construction method must therefore be adopted to install the underground thermometers, leading to increased system installation costs being about \$200-300/(m-borehole) in Japan.

One conceivable method for installing underground thermometers in this situation is to insert temperature sensors into the steel pipes employed as the foundation piles, and packing them with grout. Such pipes can have internal diameters as large as $140-200 \mathrm{~mm}$ leading to good workability. However, this method involves measuring the temperature of shallow soil that has a temperature profile [8], using a thermometer encased in a steel pipe that has a high thermal conductivity in comparison to the surrounding soil. As such, the measurement accuracy is expected to decrease. It is therefore important to evaluate the measurement accuracy of such a thermometer system.

In the present study, a numerical analysis is carried out to evaluate the measurement characteristics of an underground thermometer in a steel-pipe pile or in a borehole. The practicality of the steel-pipe approach is then verified by comparing underground temperature measurement results for borehole type and steel-pipe-pile type thermometers.

\section{Evaluation of Measurement Accuracy by Numerical Analysis}

\subsection{Numerical Analysis Model}

To evaluate the measurement accuracy for the two types of thermometer, a comparison was made of the underground temperature profile in the vertical direction at the center of a cylindrical hole in the presence or absence of a steel pipe.

Fig. 1 shows the analysis model for the case when the steel pipe is present. The pipe has an outer radius of $r_{p, o}$, an inner radius of $r_{p, i}$, and a length of $L_{p}$, and it is sunk from the ground surface into soil with uniform thermo-physical properties. The inside of the pipe is

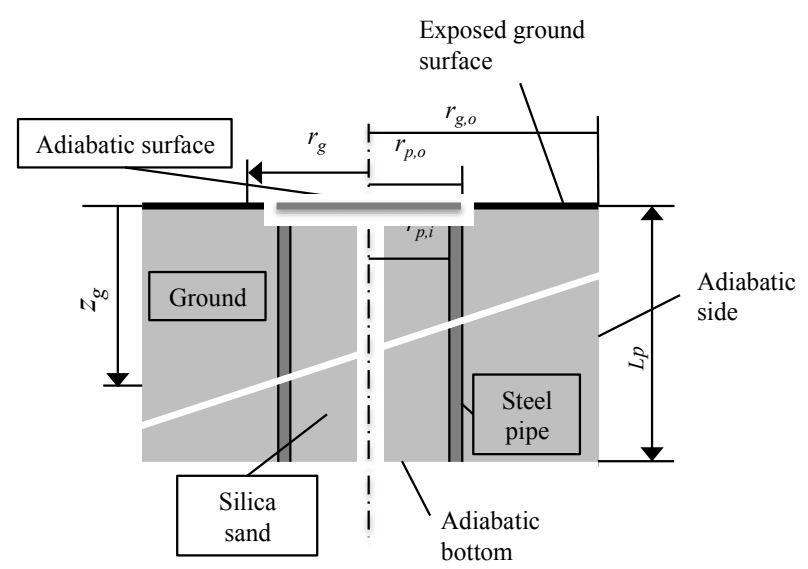

Fig. 1 Calculation model of an underground temperature with a steel pipe. 
filled with grout. The part of the pipe that is exposed on the ground surface $\left(r_{g} \leq r_{p, 0}, z_{g}=0\right)$ is assumed to be adiabatic.

In the radial direction, a location $r_{g, o}$ that is sufficiently far to be unaffected by the steel pipe is selected for measuring the underground temperature profile. In the depth direction, a point sufficiently deep $\left(z_{g}=L_{p}\right)$ to be unaffected by the thermal environment of the ground surface is selected.

In general, an extremely large number of factors must be taken into account in order to predict the underground temperature using numerical analysis, and it is extremely difficult to make an accurate prediction. These factors include the ambient temperature to which the ground surface is exposed, solar radiation and radiative cooling, the effect of wind speed, and the effects of geological formations and thermal gradients. However, beyond a certain depth, there is a region in which the temperature does not fluctuate throughout the year and this temperature (isothermal layer temperature) is considered to be closed to the mean temperature at that point. Accordingly, from an engineering perspective, the most significant factor that determines the underground temperature can be considered to be the ambient temperature. Therefore, if the isothermal layer temperature is known, the ground surface temperature can be assumed to be equal to the ambient temperature. A numerical analysis is performed to determine the underground temperature over a period of several years, and the predicted and measured annual underground temperature fluctuations are found to be in good agreement [9].

In the case of no steel pipe, thermal transfer is in the vertical direction only, and the basic formula for the underground section is

$$
\frac{\partial T_{g}}{\partial t}=a_{g} \frac{\partial^{2} T_{g}}{\partial z_{g}^{2}}
$$

In the presence of the steel pipe, heat transfer occurs only by conduction in the pipe wall, so the basic formula is

$$
\frac{\partial T}{\partial t}=a\left\{\frac{1}{r_{g}} \frac{\partial}{\partial r_{g}}\left(r_{g} \frac{\partial T}{\partial r_{g}}\right)+\frac{\partial^{2} T}{\partial z_{g}^{2}}\right\}
$$

Here, $a$ and $T$ are the thermal diffusivity and temperature of the soil, silica sand or steel pipe.

Since it can be assumed that there is no temperature gradient in the radial direction at $r=r_{g, o}$ (sufficiently far from the center of the steel pipe) nor in the vertical direction at a sufficiently deep location $z_{g}=L_{p}$, the boundary conditions including the top end of the steel pipe were as follows.

$$
\begin{gathered}
\frac{\partial T_{g}}{\partial r_{g}}=0 \quad \text { at } r_{g}=r_{g, o} \\
\frac{\partial T_{g}}{\partial z_{g}}=0 \quad \text { at } z_{g}=L_{P} \\
\frac{\partial T_{g}}{\partial z_{g}}=0 \quad \text { at } z_{g}=0,0 \leq r_{g} \leq r_{p, o} \\
T_{g}=T_{a} \quad \text { at } z_{g}=0, \quad r_{g}>r_{p, o}
\end{gathered}
$$

In the simulation, the initial conditions were determined by assuming that the underground thermometer was installed at midday on May 1 in preparation for summertime, when the underground temperature variation is large, and the steel pipe and grout were considered to be at the same temperature as the air. Also, the underground temperature on May 1 found from the annual standard temperature was taken as the initial profile for the soil temperature. Standard annual data for Koriyama City obtained from expanded AMeDAS (automated meteorological data acquisition system) weather data [10] were used for the ambient temperature data.

The difference method was used for calculations, but after confirming the accuracy by the Crank-Nicolson method, the analysis was carried out using the explicit method to simplify the calculations [14]. Previously published data $[12,15]$ were used for the physical properties of the soil. Table 1 shows the calculation conditions.

\subsection{Analysis Results}

Fig. 2 shows the underground temperature analysis 


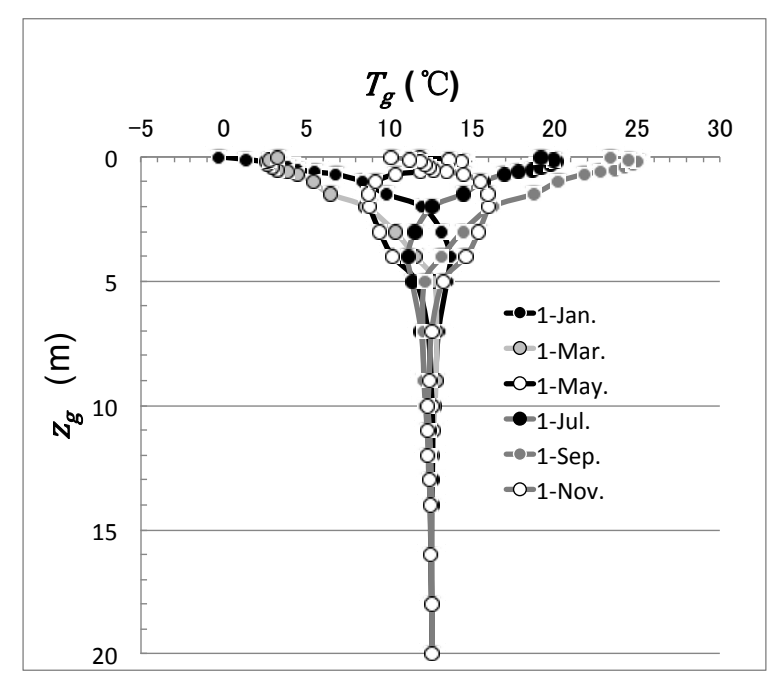

Fig. 2 Calculated results of under-ground temperature profiles at Koriyama by use of AMeDAS data.

\section{Table 1 Calculation conditions.}

\begin{tabular}{lll}
\hline$a_{g}$ & $\mathrm{~mm}^{2} / \mathrm{s}$ & 1 \\
$a_{p}$ & $\mathrm{~mm}^{2} / \mathrm{s}$ & 14 \\
$a_{s}$ & $\mathrm{~mm}^{2} / \mathrm{s}$ & 1.6 \\
$L_{P}$ & $\mathrm{~m}$ & 50 \\
$r_{p, i}$ & $\mathrm{~m}$ & 0.065 \\
$r_{p, o}$ & $\mathrm{~m}$ & 0.070 \\
\hline
\end{tabular}

results without a steel pipe for a year using Koriyama City standard annual temperature data. The value of $a_{g}$ given in Table 1 was used for the thermo-physical properties of the soil [9]. For depths of greater than 10 $\mathrm{m}$, the temperature becomes constant at $12.8^{\circ} \mathrm{C}$, and is uninfluenced by temperature fluctuations on the ground surface. This is considered to be consistent with the measurement results for the borehole type underground thermometer.

Fig. 3 shows the results for the temperature profile at the steel pipe center $\left(T_{g, p}\right)$, at the steel pipe outer wall $\left(r_{g}=0.07\right)$ and at a distance of $5 \mathrm{~m}$ at 00: $00 \mathrm{on}$ June 1. Despite the large temperature change in the depth direction, all three profiles coincide well and the ambient temperature change is found to be sufficiently transmitted to the inside of the steel pipe. This demonstrates that the influence of heat conduction in the steel pipe walls is small in the vertical direction.

Fig. 4 shows the difference between the temperature at the center of the grout-filled steel-pipe pile, $T_{g, p}$, and the underground temperature, $T_{g}$, in the vertical

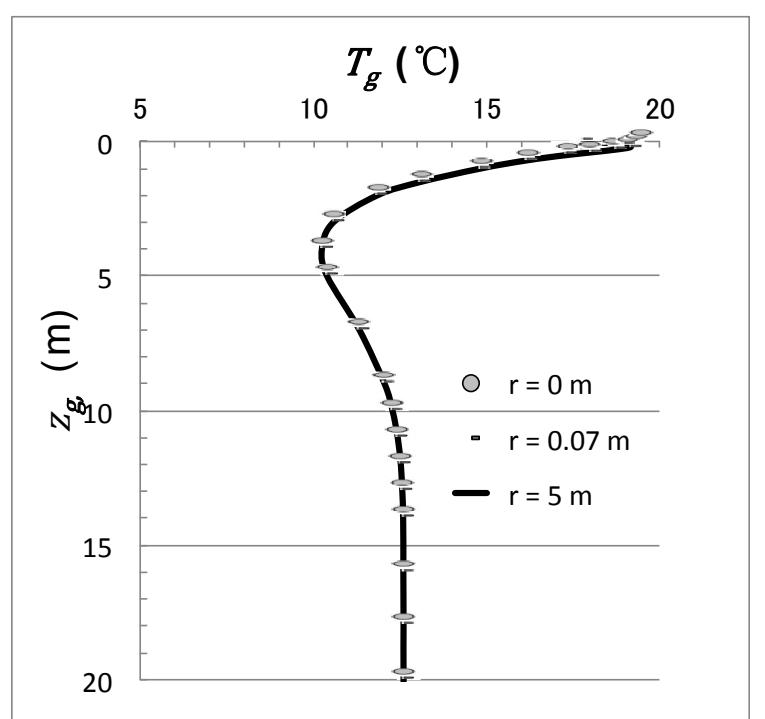

Fig. 3 Calculated underground temperature profiles for steel pipe on June 1.

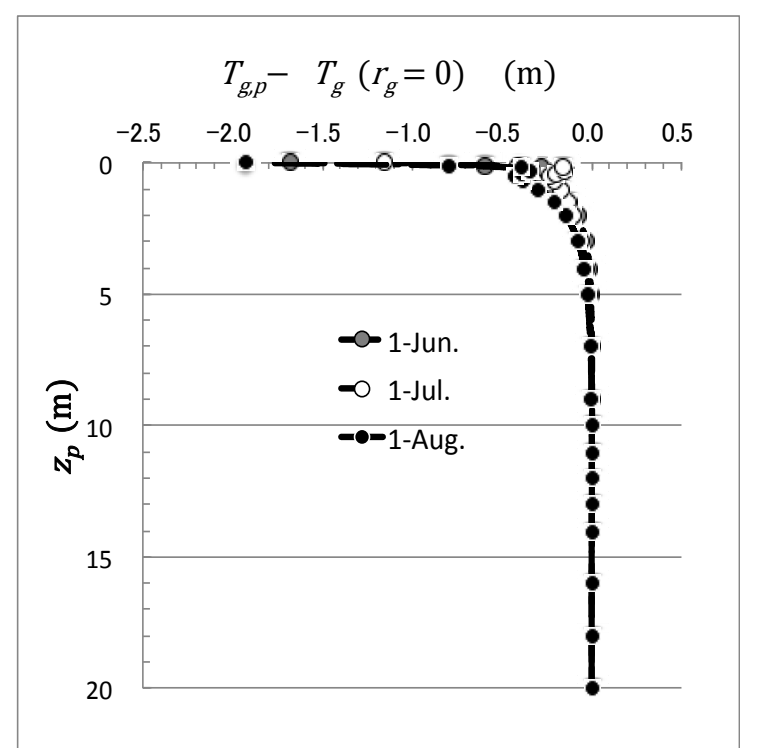

Fig. 4 Measurement accuracy of under-ground thermometer with a steel pipe.

direction. The time of the comparison was $0: 00$ on the 1st day of each month from June to August. The change in underground temperature is the greatest at the ground surface, and the error is large at around $2{ }^{\circ} \mathrm{C}$ because of the insulation at the steel pipe surface. Meanwhile, the error for the underground temperature at a depth of $0.1 \mathrm{~m}$ or more is $\leq 0.5^{\circ} \mathrm{C}$.

The temperature measurement error is large for a very shallow surface layer in the case of the steel-pipe-pile underground thermometer, but this error becomes small at depths of $0.1 \mathrm{~m}$ or more, and the thermometer 
is found to have sufficient accuracy for underground temperature management using geothermal heat.

\subsection{Results of Measurements for Actual Soil}

An empirical comparison was made of the measurement results for a borehole underground thermometer and two steel-pipe-pile underground thermometers $\mathrm{A}$ and $\mathrm{B}$, which had the same structure as that used in the numerical analysis. Thermometers were installed in the schoolyard of the old Akatsu Elementary School in Akatsu, Konan town, Koriyama City. The borehole underground thermometer and steel-pipe-pile underground thermometers were separated by around $40 \mathrm{~m}$, and the steel-pipe-pile underground thermometers A and B were separated by about $5 \mathrm{~m}$. This location is $50 \mathrm{~km}$ west from the center of Koriyama City and at an altitude of $510 \mathrm{~m}$, making the temperature around $2-3{ }^{\circ} \mathrm{C}$ lower than that at the Koriyama City center. To determine the thermo-physical properties of the soil at this location, a core sample was taken and subjected to a thermal response test, which indicated that the thermal diffusivity was lower than that used in the numerical analysis $\left(0.5 \mathrm{~mm}^{2} / \mathrm{s}\right.$ or less). Thus, the thermal diffusivity of the soil was lower than that of the steel pipe.

Fig. 5 shows the schematic diagrams of a borehole and a steel-pile pipe thermometer. After drilling a $\Phi 180 \mathrm{~mm}$ diameter-hole $10 \mathrm{~m}$ down from the ground surface, reinforcing the walls, and inserting a type- $T$ thermocouple for the borehole underground thermometer, the borehole was filled with the same silica sand No. 5 in such a way as to prevent cavities from forming. For the steel-pipe-pile underground thermometers, a $\Phi 139.5 \mathrm{~mm}$ outer-diameter steel-pipe pile was driven $7 \mathrm{~m}$ into the ground, after which a similar type-T thermocouple was installed and the pipe was filled with the same silica sand No. 5. Temperature inspections including reproducibility were performed for all thermocouples using a thermally regulated bath and the maximum relative error was $0.1^{\circ} \mathrm{C}$.

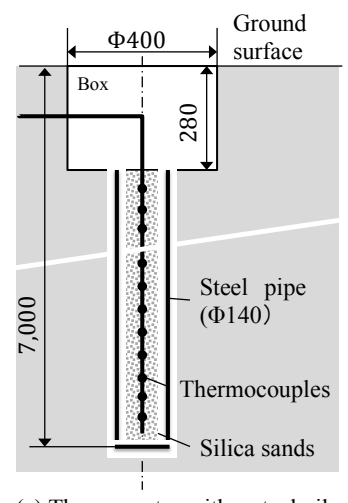

(a) Thermometer with a steel pile

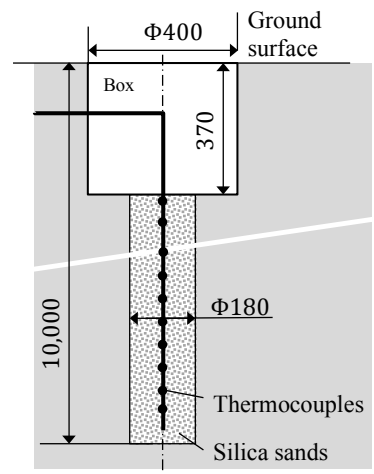

(b) Thermometer with a borehole
Fig. 5 Schematic diagram of underground thermometer with a steel pipe and a borehole.

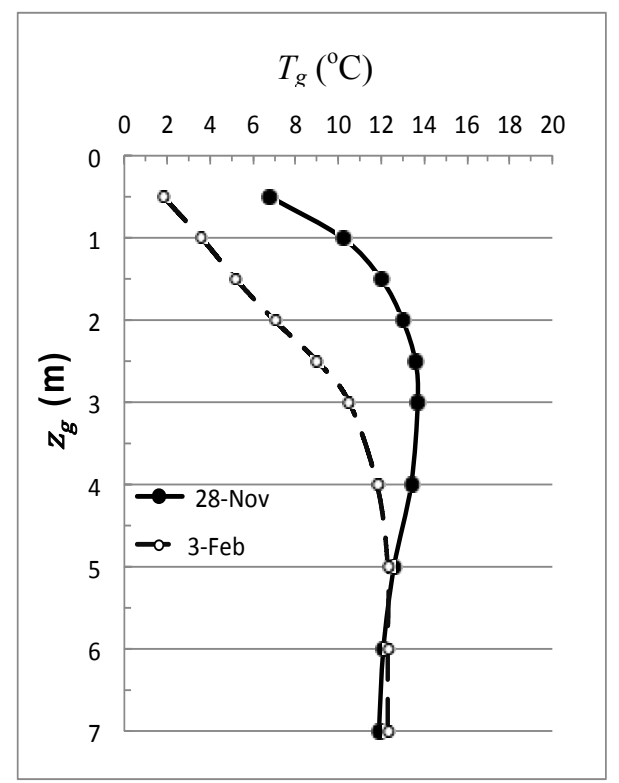

Fig. 6 Underground temperature profiles measured by borehole type thermometer.

Fig. 6 shows the temperature determined by the borehole type thermometer at 12: 00 noon on November 28, 2015, and on February 3, 2016. The maximum temperature on November 28 occurs at a depth of $3 \mathrm{~m}$. Meanwhile, February 3 is in the late winter and the ground surface temperature is low, so the underground temperature is found to decrease from $5 \mathrm{~m}$ to shallower depths. In this way, a comparison of the measurement results for both types of thermometer was made with respect to differing underground temperature profiles.

Figs. 7 and 8 show the measured underground temperatures for the borehole and the steel-pipe-pile 


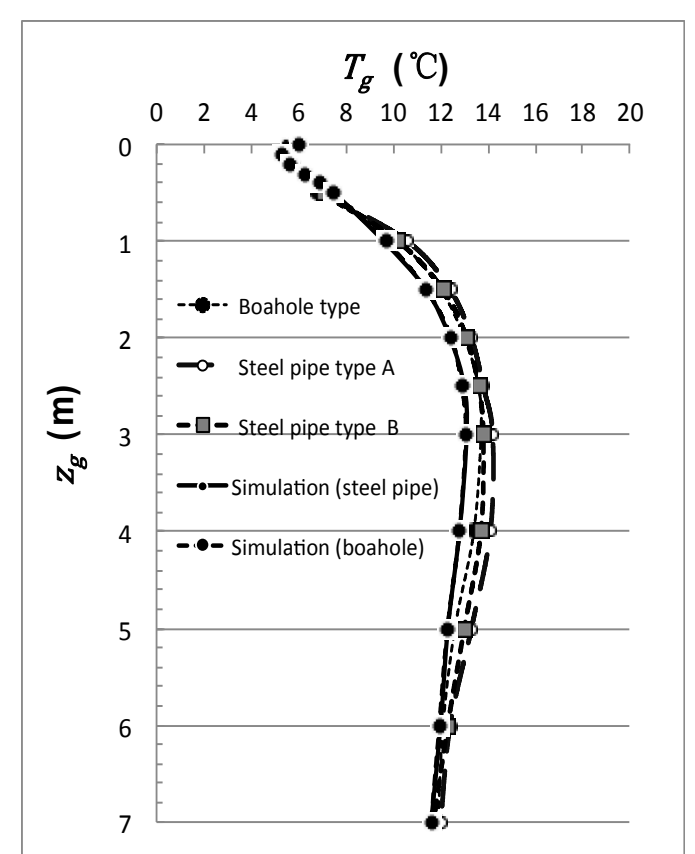

Fig. 7 Underground temperature profiles at noon, November 28, 2015.

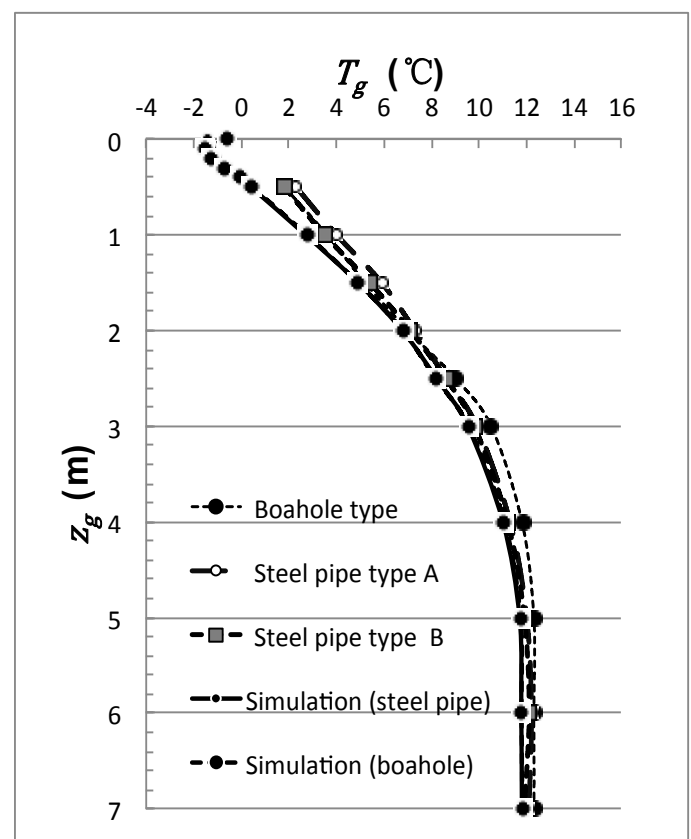

Fig. 8 Underground temperature profiles at noon, February 3, 2016.

type thermometers at 12: 00 on November 28 and February 3, respectively. Also, calculated results are shown, too. Under calculation, $a_{g}$ is used to be 0.5 $\mathrm{mm}^{2} / \mathrm{s}$ based on the thermal properties measurements of the ground-core-sample, and the hourly average atmospheric temperature is used at Inawashiro
AMeDAS data near Akatsu provided by Japan Metrological Agency. Calculation method is the same in Section 2.1. At a depth of around 3-4 m, there is a difference of about $1{ }^{\circ} \mathrm{C}$ between the steel-pipe type A and the borehole type thermometer.

Also calculation results are different from measurement results in Figs. 7 and 8. There is also a difference between the temperatures measured by the steel-pipe type A and B thermometers. This may be because the ground is not completely uniform even at the same site. Taking this point into consideration, the steel-pipe-pile type thermometer can be considered to follow the temperature changes of the ground closely, despite the difference in underground temperature profiles on November 28 and February 3.

\section{Conclusions}

Underground temperature management is important in the case of long-term operation of shallow geothermal heat use systems, because they are susceptible to temperature changes in the surface layer. A borehole type underground thermometer can be used to measure underground temperatures, but the installation method differs in the case of using steel-pipe foundation piles, making the installation cost of the underground thermometer an issue. A conceivable alternative is to use a steel-pipe pile that has not been converted into an underground heat exchanger as a thermometer. However, the thermal diffusivity of the steel pipe wall is much higher than that of the surrounding soil, leading to the danger of a large error occurring during shallow temperature measurements, since the underground temperature profile is not uniform. Accordingly, we performed a numerical analysis and an empirical verification of the results. The results indicated that the impact on the measurement accuracy for heat transfer in the vertical direction via the steel pipe wall was small, and measurement values track underground temperature changes sufficiently well, demonstrating the measurement method to be sufficiently applicable for temperature management. 


\section{Acknowledgments}

The present study was conducted under the R\&D Program of New Energy and Industrial Technology Development Organization. The authors would like to express appreciation to Mr. Takeshi Matsumoto of Nippon Koei Co., Ltd. for his assistance in the measurements.

\section{References}

[1] Chung, J. T., and Choi, J. M. 2012. "Design of Performance Study of the Ground-Coupled Heat Pump System with an Operating Parameter." Renewable Energy 42 (June): 118-24.

[2] Fisher, D. E., Rees, S. J., Padhmanabhan, S., and Murugappan, A. 2006. "Implement and Validation of Ground-Source Heat Pump System Models in an Integrated Building and System Simulation Environment." HVAC \& R Research 12 (3): 693-710.

[3] Sayyadi, H., and Nejatolahi, M. 2011.“Thermodynamics and Thermo-Economics Optimization of a Cooling Tower-Assisted Ground Source Heat Pump."
Geothermics 40 (3): 221-32.

[4] Huo, K. C., Qin, X., and Yue, H. H. 2013. "Research on Uplift Static Load Test of Large-Diameter Steel Pipe Pile Based on Mechanics." Applied Mechanics and Materials 256-259: 410-5.

[5] Kato, K. 2011. "Conceptual House with LOHAS for Energy Independence and Living With Nature." Journal of JSME 115 (1126): 664-7.

[6] Fukushima Technology Center. 2014. Development of GSHP System with Pile Heat Exchangers. Researching Report of Fukushima Technology Center.

[7] Ground Source Heat Pump System Laboratory, Hokkaido University. 2011. "Ground Source Heat Pump System." Ohmsha, Japan.

[8] Oguma, M., Matsumoto, T., and Kakizaki, T. 2014. "Numerical Simulation of a Ground Source Heat Pump System with Pile Heat Exchangers." ASME Journal of Thermal Science and Engineering Applications 7 (1): 014501.

[9] Oguma, M., Matsumoto, T., and Kakizaki, T. 2013. "Numerical Simulation of a Ground Source Heat Pump System Using Pile Heat Exchangers." In Proceedings of the ASME 2013 Heat Transfer Summer Conference, V001T01A017-1-10. 